OPEN ACCESS

Edited by:

Peter G. Bruce,

University of St. Andrews, UK

Reviewed by:

Shuhui Sun,

Institut National de la Recherche

Scientifique, Canada

Zhongwei Chen,

University of Waterloo, Canada

${ }^{*}$ Correspondence:

Xingcheng Xiao,

Chemical and Materials Systems

Laboratory, General Motors R\&D

Center, 30500 Mound Road,

MC:480-106-RA1,

Warren, MI 48090, USA

xingcheng.xiao@gm.com

Specialty section:

This article was submitted to Energy Storage, a section of the journal Frontiers in Energy Research

Received: 06 January 2015

Accepted: 20 April 2015

Published: 30 June 2015

Citation:

Ahn D and Xiao X (2015) Enhanced rate capability of oxide coated lithium titanate within extended voltage ranges.

Front. Energy Res. 3:21. doi: 10.3389/fenrg.2015.00021

\section{Enhanced rate capability of oxide coated lithium titanate within extended voltage ranges}

\author{
Dongjoon Ahn ${ }^{1}$ and Xingcheng Xiao ${ }^{2 *}$ \\ ${ }^{1}$ College of Engineering, University of Kentucky, Lexington, KY, USA, ${ }^{2}$ Chemical and Materials Systems Laboratory, General \\ Motors R\&D Center, Warren, MI, USA
}

Lithium titanate $\left(\mathrm{Li}_{4} \mathrm{Ti}_{5} \mathrm{O}_{12}\right.$ or $\left.\mathrm{LTO}\right)$ is a promising negative electrode material of high-power lithium-ion batteries, due to its superior rate capability and excellent capacity retention. However, the specific capacity of LTO is less than one half of that of graphite electrode. In this work, we applied ultrathin oxide coating on LTO by the atomic layer deposition technique, aiming for increasing the energy density by extending the cell voltage window and specific capacity of LTO. We demonstrated that a few nanometer thick $\mathrm{Al}_{2} \mathrm{O}_{3}$ coating can suppress the mechanical distortion of LTO cycled at low potential, which enable the higher specific capacity and excellent capacity retention. Furthermore, the surface coating can facilitate the charge transfer, leading to significantly improved rate capabilities, comparing with the uncoated LTO.

Keywords: lithium titanate, atomic layer deposition, surface coating, rate capability, oxide coating

\section{Introduction}

Since the energy crisis from the shortage of fossil fuel, it is indispensable to develop electrical energy storage devices from the alternative energy sources such as batteries. Among many battery chemistries, lithium-ion batteries (LIBs) are now in great demand because of its high-energy density (Tarascon and Armand, 2001) as the power source from small electronics to the transportation application especially for the electrification of power train system of cars. However, several problems such as short cycle life and poor abuse tolerance are still the main challenges, which result from both mechanical and chemical degradation. Short cycle life was resulted from the mechanical degradation of particles in the electrode caused by the volume expansion and contraction when LIBs were charged and discharged repeatedly. Solid-electrolyte interphase (SEI) layer, which forms as a result of the liquid electrolyte decomposing that initiates at $<0.8 \mathrm{~V} \mathrm{vs}$. $\mathrm{Li}^{\prime} / \mathrm{Li}^{+}$, also can greatly impact the battery's capacity, rate capability, and cycle life.

Lithium titanate $\left(\mathrm{Li}_{4} \mathrm{Ti}_{5} \mathrm{O}_{12}, \mathrm{LTO}\right)$ was a spinel structure and known as a zero strain material (Ohzuku et al., 1995; Ronci et al., 2002). In LTO, a redox couple from $\mathrm{Ti}^{4+}$ to $\mathrm{Ti}^{3+}$ reversibly delivered the electron and the two-phase transition process between spinel and rock salt was occurred at $1.55 \mathrm{~V}$ vs. $\mathrm{Li} / \mathrm{Li}^{+}$(Aldon et al., 2004; Takami et al., 2011). Since it has very low-volume expansion and higher working potential, LTO is an emerging anode material that can solve the above mentioned problems. However, the cut-off voltage of LTO electrode is normally controlled from 2.5 to $1 \mathrm{~V}$ vs. $\mathrm{Li} / \mathrm{Li}^{+}$to avoid SEI formation and quasi-rock salt phase formation at low potential (Lu et al., 2007). As a result, it has a specific capacity of $155 \mathrm{mAhg}^{-1}$ and an energy density of $270 \mathrm{Whkg}^{-1}$ (Colbow et al., 1989; Zaghib et al., 1998), which is, in fact, a limitation to compete other negative electrodes such as graphite in terms of energy density. 
Hsieh and Lin cycled LTO down to $0.01 \mathrm{~V}$ in order to exploit the extra capacity at lower potential (Ronci et al., 2002) with the belief that it would not only facilitate the enhanced reversible capacity but also give a wider working voltage to improve the energy density of lithium-ion batteries. Their results, however, also showed a continuous degradation of capacity at a lower potential condition upon repeating the charge and discharge cycle. Wang's work on in situ synchrotron clearly shows the structural distortion in LTO when it is cycling at low potentials (Wang et al., 2012), although significantly increased specific capacity can be extracted out.

Most of undesirable side reactions, such as electrolyte decomposition, gas generation, and SEI formation, occur on the electrode surface in contact with electrolyte. On the other hand, the microcrack formation, propagation, and electrode material pulverization also initiate from electrode surface. Rationally, among the many approaches to improving cycle performance, the surface modification of electrode material has been suggested as an efficient approach to improve cycling stability and rate capability to enhance lithium-ion battery performance (Chen et al., 2010). However, the surface coating normally introduces extra resistance for charge transfer at the electrode surface. Therefore, there should be an optimum film, which can suppress the chemical side reactions, and provide mechanical protections, and meanwhile should be thin enough without introducing too much impedance to deteriorate the battery performance. Atomic layer deposition (ALD) is also a very promising technique to develop pin-hole free, ultrathin coating. It has been demonstrated that a few atomic layers of oxide deposition by ALD can significantly enhance the cycle life of both positive and negative electrode and several works such as natural graphite (Jung et al., 2010a,b), $\mathrm{MoO}_{3}$ (Riley et al., 2010), $\mathrm{LiCoO}_{2}$ (Jung et al., 2010a,b), and nano-sized $\mathrm{LiCoO}_{2}$ (Scott et al., 2011).
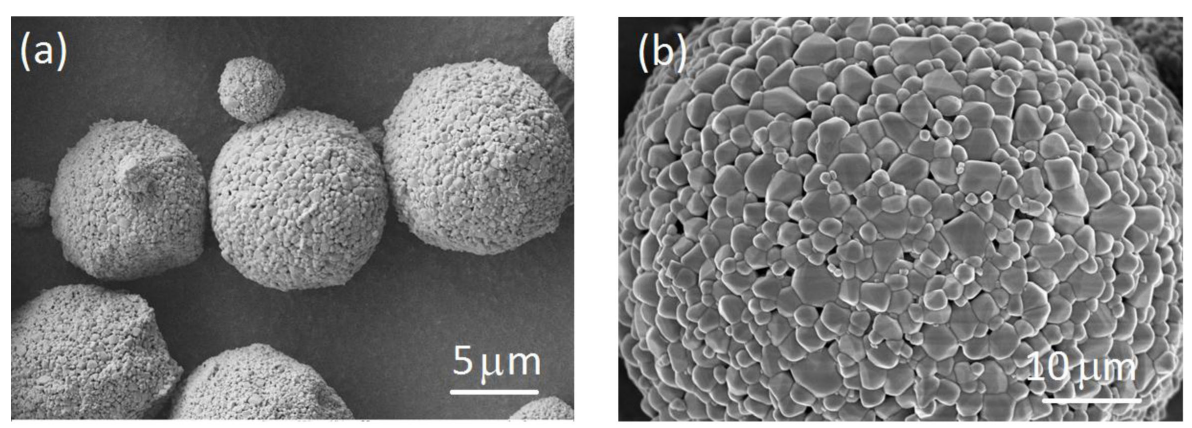

FIGURE 1 | Scanning electron microscopic (SEM) images of the pristine LTO particle. (A) Low magnification; (B) High magnification.
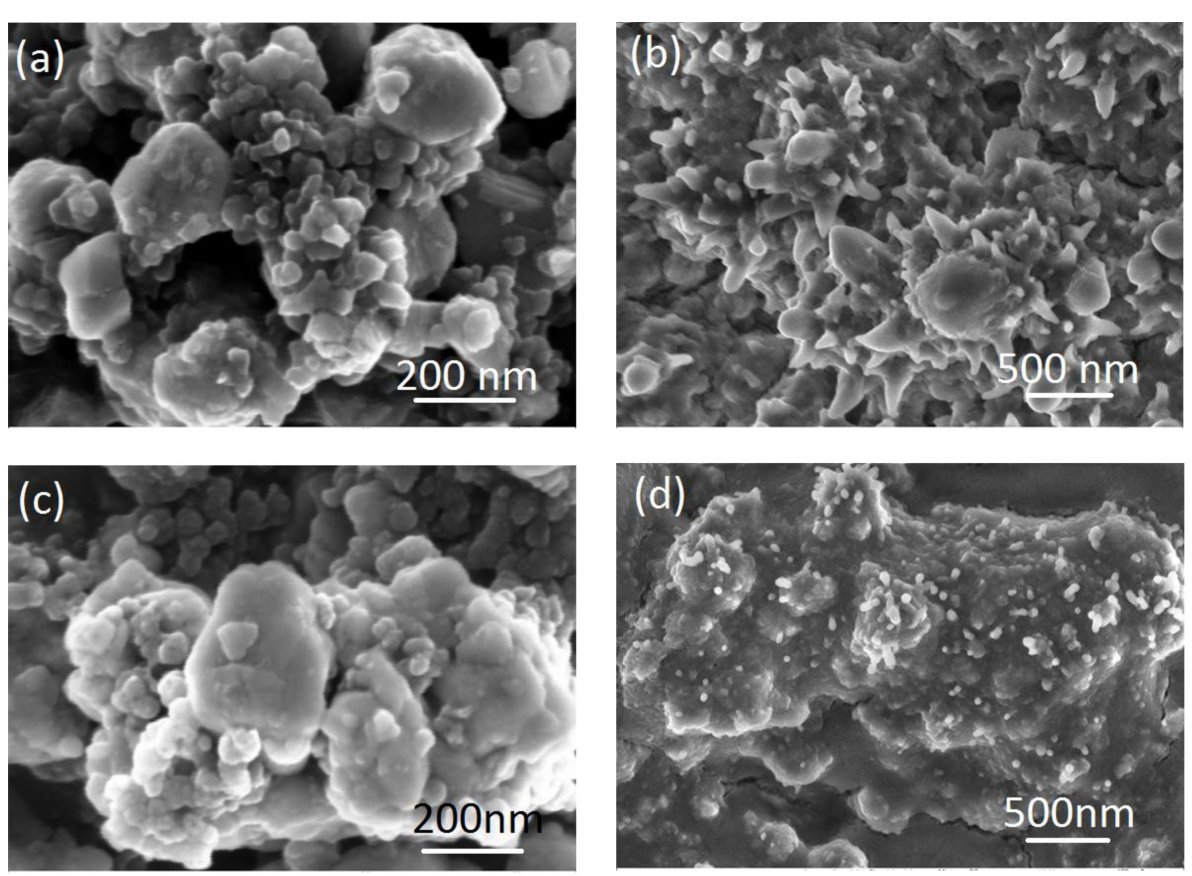

FIGURE 2 | SEM images of $\mathrm{Al}_{2} \mathrm{O}_{3}$ coated and bare LTO electrode before/after cycling; bare LTO electrode before (A)/after (B) cycling and $\mathrm{Al}_{2} \mathrm{O}_{3}$-coated LTO electrode before (C)/after (D) cycling. 

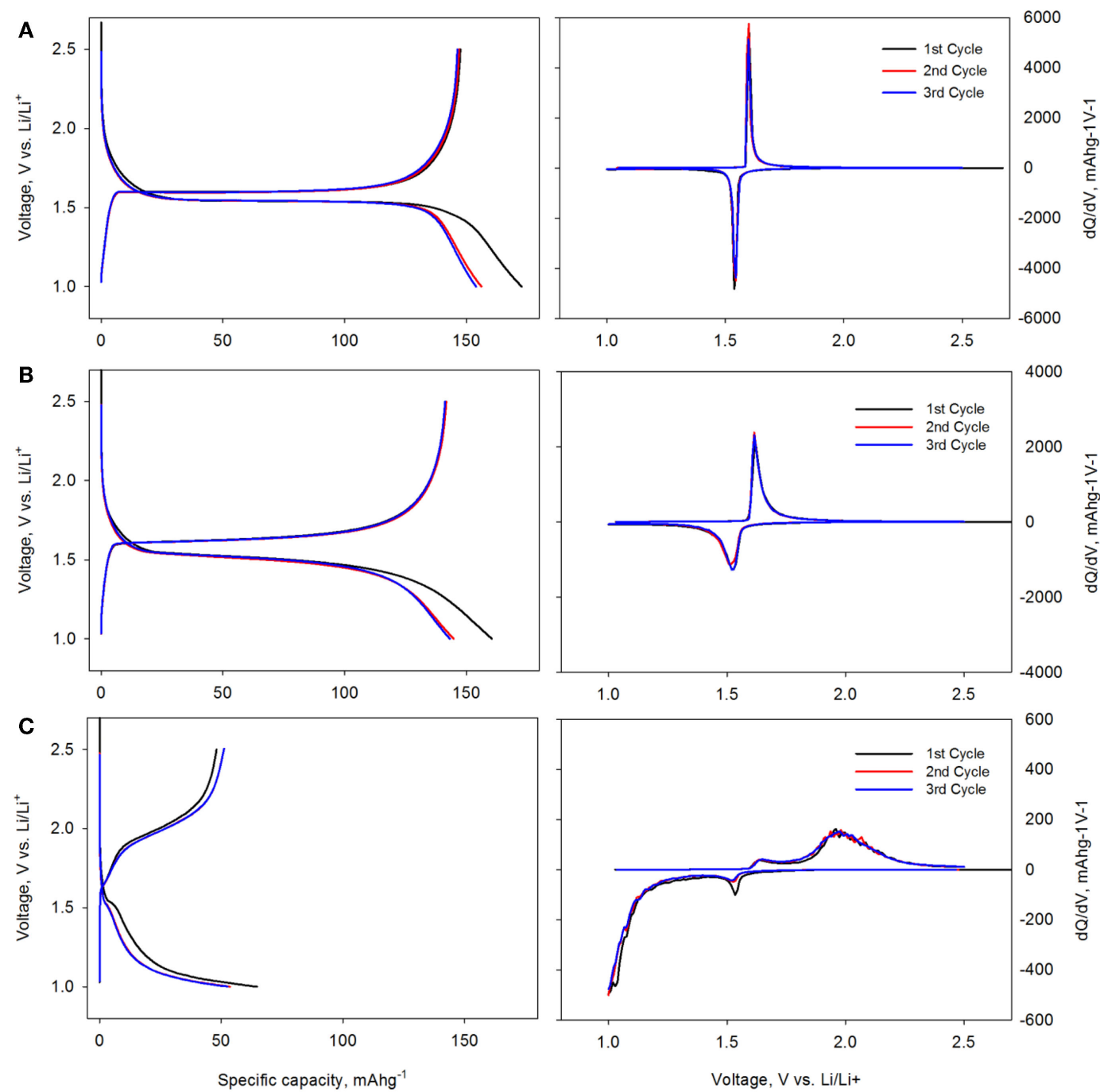

FIGURE 3 | Voltage profile (left) and differential capacity plot (right) of the pristine $\mathrm{LTO}$ (A), $2.2 \mathrm{~nm} \mathrm{Al}_{2} \mathrm{O}_{3}$-coated LTO (B) and $5.5 \mathrm{~nm} \mathrm{Al} \mathrm{O}_{3}-\mathrm{coated} \mathrm{LTO}$ (C) electrode with normal potential window from 2.5 to $1 \mathrm{~V}$ vs. $\mathrm{Li}^{\mathrm{L}} \mathrm{Li}^{+}$.

Our recent investigation shows that the surface modification on nano-sized LTO can significantly increase the capacity without capacity fading (Ahn and Xiao, 2011). In this work, we further investigate ultrathin $\mathrm{Al}_{2} \mathrm{O}_{3}$ layer on LTO to enhance the rate capability particularly, and increase the capacity under lower cut-off voltage window.

\section{Experimental}

\section{Electrode Fabrication and $\mathrm{Al}_{2} \mathrm{O}_{3}$ Coating}

The LTO electrode was fabricated by doctor blade method with a slurry of 80 w.t.\% LTO powder (Ishihara Sangyo Chemical, Japan), 10 w.t.\% carbon black (Alfa-Aesar, USA), and 10 w.t.\% polyvinylidene (PVDF, Alfa-Aesar, USA). 1-Methyl-2-pyrrolidinone (NMP, Alfa-Aesar, USA) was used as the solvent and as-made electrode was dried at $180^{\circ} \mathrm{C}$ in vacuum oven overnight. $\mathrm{Al}_{2} \mathrm{O}_{3}$ layer was deposited on LTO electrode under vacuum chamber at $180^{\circ} \mathrm{C}$ and sequential surface reaction between trimethylaluminum (TMA, deposition grade, Sigma-Aldrich, USA) and high-performance liquid chromatography grade $\mathrm{H}_{2} \mathrm{O}$ (Sigma-Aldrich, USA) was produced a mono-layer-thick $\mathrm{Al}_{2} \mathrm{O}_{3}$ film with thickness of $0.11 \mathrm{~nm}$.

\section{Characterization}

The morphology and nanostructure of the LTO- and $\mathrm{Al}_{2} \mathrm{O}_{3}$ coated LTO were examined with a LEO 230 field emission scanning electron microscopy at an acceleration voltage of $5 \mathrm{kV}$. Differential scanning calorimetry (DSC, TA, USA) experiments were used to investigate the thermal stability of the $\mathrm{Al}_{2} \mathrm{O}_{3}$-coated LTO electrode at the normal operating temperature of batteries.

\section{Electrochemical Tests}

$\mathrm{Al}_{2} \mathrm{O}_{3}$-coated LTO electrodes were used as the working electrode in the form of CR-2032 coin cells with pure lithium metal foil as both reference and counter electrode. Microporous tri-layered polypropylene $(\mathrm{PP})$ and polyethylene $(\mathrm{PE})$ polymer membrane 

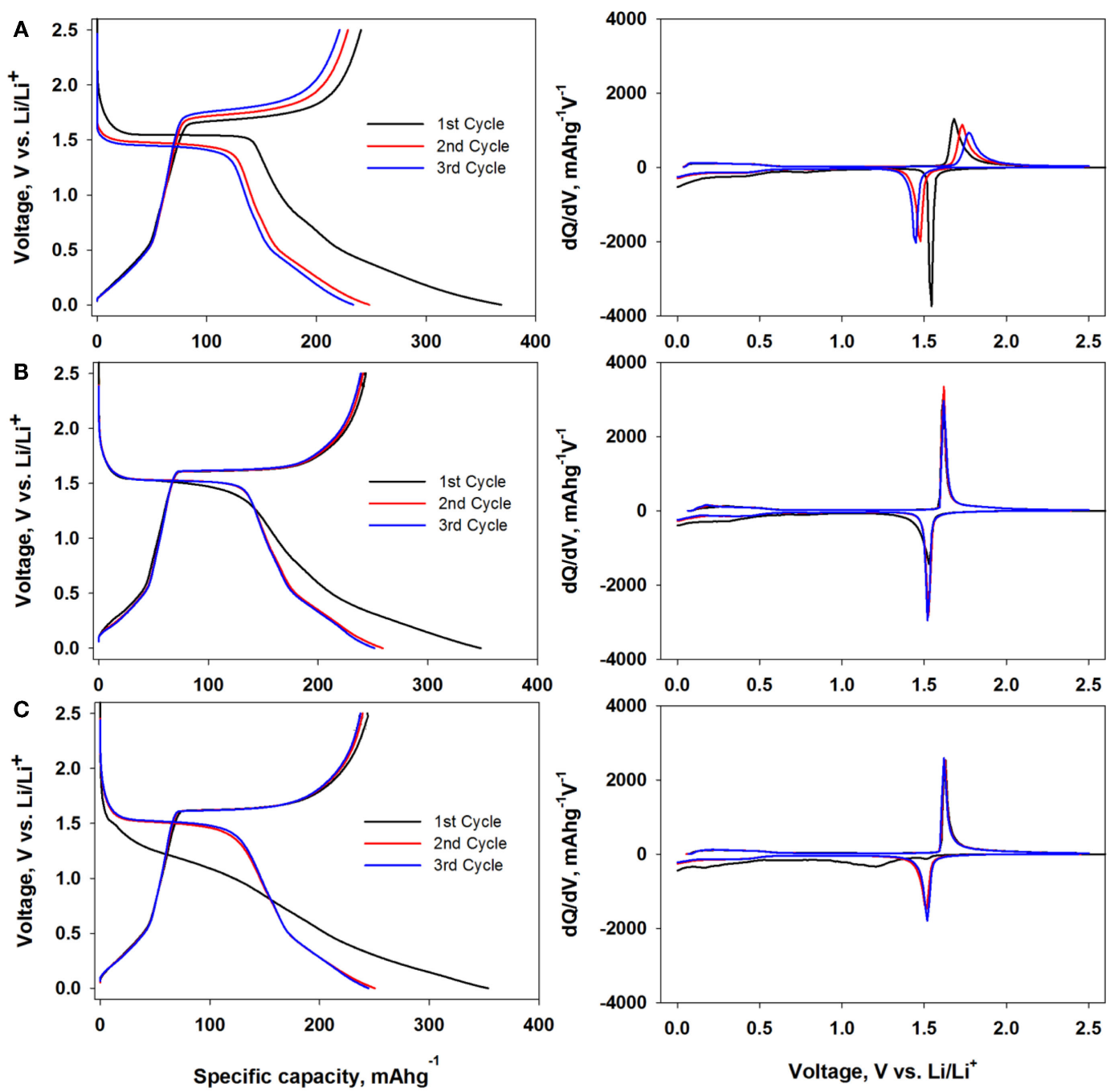

FIGURE 4 | Voltage profile (left) and differential capacity plot (right) of the bare LTO (A), $2.2 \mathrm{~nm} \mathrm{Al} \mathrm{O}_{3}$-coated LTO (B) and $5.5 \mathrm{~nm} \mathrm{Al} \mathrm{O}_{3}-\mathrm{coated} \mathrm{LTO}$ (C) electrode with lower potential window from $2.5 \mathrm{~V}$ to $1 \mathrm{mV} \mathrm{vs.} \mathrm{Li} / \mathrm{Li}^{+}$.

(Celgard, USA) and $1 \mathrm{M} \mathrm{LiPF}_{6}$ in a mixed solution of ethylene carbonate and diethyl carbonate (1:1 volume ratio, Novolyte, USA) were selected as the separator and electrolyte, respectively. The electrochemical measurements were performed with the constant current density of $50 \mathrm{mAg}^{-1}$ at a cut-off voltage of $1 \mathrm{mV} \sim 2.5 \mathrm{~V}$ vs. $\mathrm{Li} / \mathrm{Li}^{+}$. Alternating current (AC) impedance spectroscopy was used to investigate the formation of the SEI layer and the charge transfer resistance of $\mathrm{Al}_{2} \mathrm{O}_{3}$-coated LTO electrode under galvanostatic and potentiostatic conditions.

\section{Results and Discussion}

Scanning electron microscopic (SEM) images of the pristine LTO particles shown in Figure 1. The LTO particles are welldefined spheres with diameters ranged from 2 to $10 \mu \mathrm{m}$. Each LTO particle is also composed of numerous nano-size primary particulate and pores in LTO spherical structures. LTO has a nanoporous structure that allows the electrolyte to penetrate inside the particles, resulting in high accessibility of the active material
(Amine et al., 2010). In addition, the nano-primary particles of LTO allow fast lithium diffusion because of the shorter lithium diffusion path within the nanoparticle (Liao et al., 2013, 2014). Both bare LTO electrode and $\mathrm{Al}_{2} \mathrm{O}_{3}$-coated electrode were also shown in Figures 2A,B and morphological changes upon cycling were investigated through SEM and represented in Figures 2C,D.

To compare the electrochemical behavior of $\mathrm{Al}_{2} \mathrm{O}_{3}$-coated LTO and the pristine LTO with different cut-off potential, voltage profile, and differential capacity plots were presented in Figures 3 and 4. In Figure 3, cut-off potential was set as $2.5 \sim 1 \mathrm{~V}$ vs. $\mathrm{Li} / \mathrm{Li}^{+}$ and constant current $\left( \pm 25 \mathrm{mAg}^{-1}\right)$ was applied at charge and discharge cycle without any voltage hold. Two-phase transition between spinel to rock salt structure was shown at $1.55 \mathrm{~V}$ vs. $\mathrm{Li} / \mathrm{Li}^{+}$in the prinstine LTO (Figure 3A) and reversible capacity was close to the theoretical capacity $\left(155 \mathrm{mAhg}^{-1}\right)$. There was no any significant capacity loss and polarization increase within three cycles and two peaks at 1.53 and $1.59 \mathrm{~V}$ were developed as the discharge and charge reaction potential, respectively. As $\mathrm{Al}_{2} \mathrm{O}_{3}$ layer thickness increased, however, two-phase transition 
plateau was continuously reduced and polarization between discharge and charge cycle was also enlarged. Apparently, the lithium insertion to LTO was not same as the pristine LTO and two-phase transition was not occurred by insulating oxide layer. Also, the capacity of $5.5 \mathrm{~nm} \mathrm{Al} \mathrm{O}_{3}$-coated LTO was decreased to $2 / 3$ of the pristine LTO capacity.

In Figure 4, each cell was charged and discharged with same constant current as Figure 3 but set the cut-off potential from $2.5 \mathrm{~V}$ to $1 \mathrm{mV}$. Due to the lower potential window, total reversible capacity of all three electrodes was increased to $220 \mathrm{mAhg}^{-1}$ and there was no considerable capacity change among these three electrodes. For the pristine LTO (Figure 4A), $100 \mathrm{mAhg}^{-1}$ additional capacity was obtained by lower cut-off potential window because more lithium was inserted to LTO and quasi-rock salt phase was started to form below $1 \mathrm{~V}$ vs. $\mathrm{Li} / \mathrm{Li}^{+}$(Lu et al., 2007). However, the further lithium insertion resulted in the structural damage to LTO and led to continuous capacity fading. The differential capacity plot of the pristine LTO showed the polarization between charge and discharge cycle. The overpotential was mitigated in both 2.2 and $5.5 \mathrm{~nm}$ coated LTO electrodes. Interestingly, the voltage profiles at first discharge cycle of three electrodes represented not only the reduction of two-phase transition regime but also the additional lithium intercalation into $\mathrm{Al}_{2} \mathrm{O}_{3}$ layers. Due to the large amount of lithium intercalation to $\mathrm{Al}_{2} \mathrm{O}_{3}, \mathrm{Al}_{2} \mathrm{O}_{3}$ would transform into Li-containing $\mathrm{Al}_{2} \mathrm{O}_{3}$ component and it might also react with $\mathrm{HF}$ in electrolyte to form $\mathrm{Li}-\mathrm{Al}_{2} \mathrm{O}_{3}-\mathrm{AlF}$ compound (Oh et al., 2010; Xiao et al., 2011). Followed by this activation process, $\mathrm{Al}_{2} \mathrm{O}_{3}$ layer would develop into $\mathrm{Li}^{+}$conducting film and two-phase transition plateau reappeared after first discharge cycle.

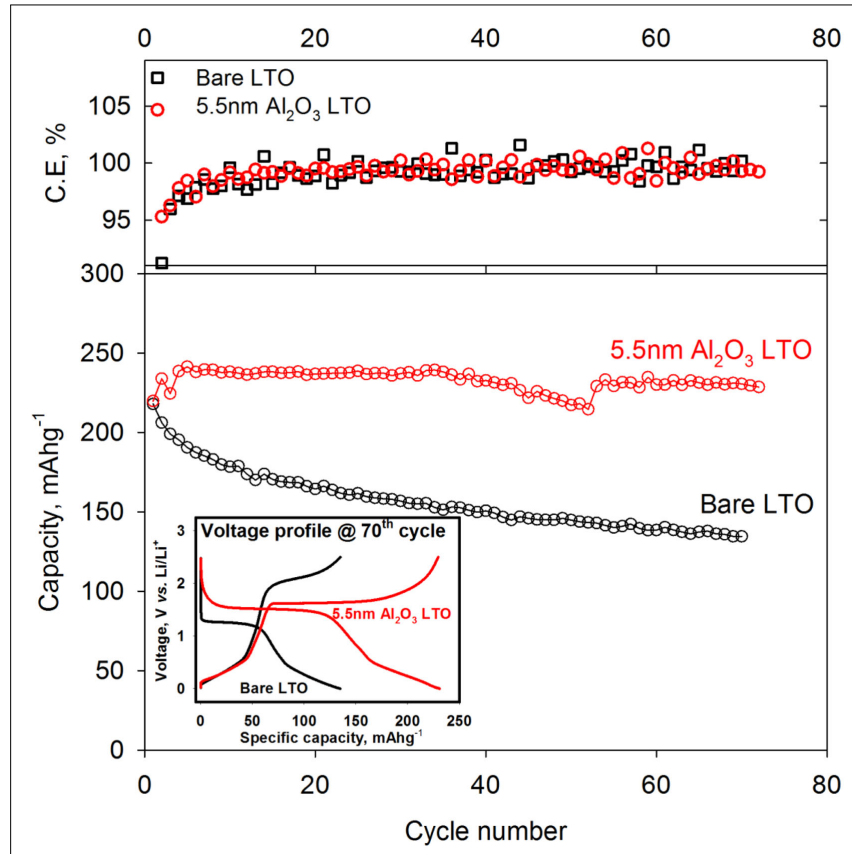

FIGURE 5 | Capacity retention and Coulombic efficiency of the pristine LTO (black) and $5.5 \mathrm{~nm} \mathrm{Al} \mathbf{O}_{3}$-coated LTO (red) electrode. Both charging and discharging current densities were $50 \mathrm{mAg}^{-1}$ and upper and lower cut-off potential were set as $2.5 \mathrm{~V}$ and $1 \mathrm{mV}$ vs. $\mathrm{Li} / \mathrm{Li}^{+}$, respectively. The inserted figure presented the voltage profile at 70 th cycle both electrodes.
The activation of $\mathrm{Al}_{2} \mathrm{O}_{3}$ was related to the amount of lithium inserted to $\mathrm{Al}_{2} \mathrm{O}_{3}$ and lower potential window was critical for $\mathrm{Al}_{2} \mathrm{O}_{3}$-coated LTO electrode at lower potential.

To compare the cyclic stability between the pristine LTO- and $\mathrm{Al}_{2} \mathrm{O}_{3}$-coated LTO, both capacity and Coulombic efficiency vs. cycle number were shown in Figure 5. Overall capacity retention of $\mathrm{Al}_{2} \mathrm{O}_{3}$-coated LTO at lower potential window was more stable than the pristine LTO and the capacity loss was almost zero at 70th cycle. However, capacity of the pristine LTO was continuously decreased cycle by cycle and only $60 \%$ of its initial capacity was retained at 70th cycle later. Capacity fading of the bare LTO was due to the structural breakdown to quasi-rock salt phase at the lower potential (Ohzuku et al., 1995; Cho et al., 2001). Additionally, SEI layer would formed at the surface of the pristine LTO electrode under lower potential window $<0.8 \mathrm{~V}$ vs. $\mathrm{Li} / \mathrm{Li}^{+}$ (Bryngelsson et al., 2007), the distortion of LTO might damage SEI layer at lower potential, leading to lower cycle efficiency. However, $\mathrm{Al}_{2} \mathrm{O}_{3}$ coating can significantly suppress the SEI formation (Xiao et al., 2011). Therefore, thin layer of oxide made significant improvement for LTO electrode performance and it would be more durable not only mechanically but also chemically
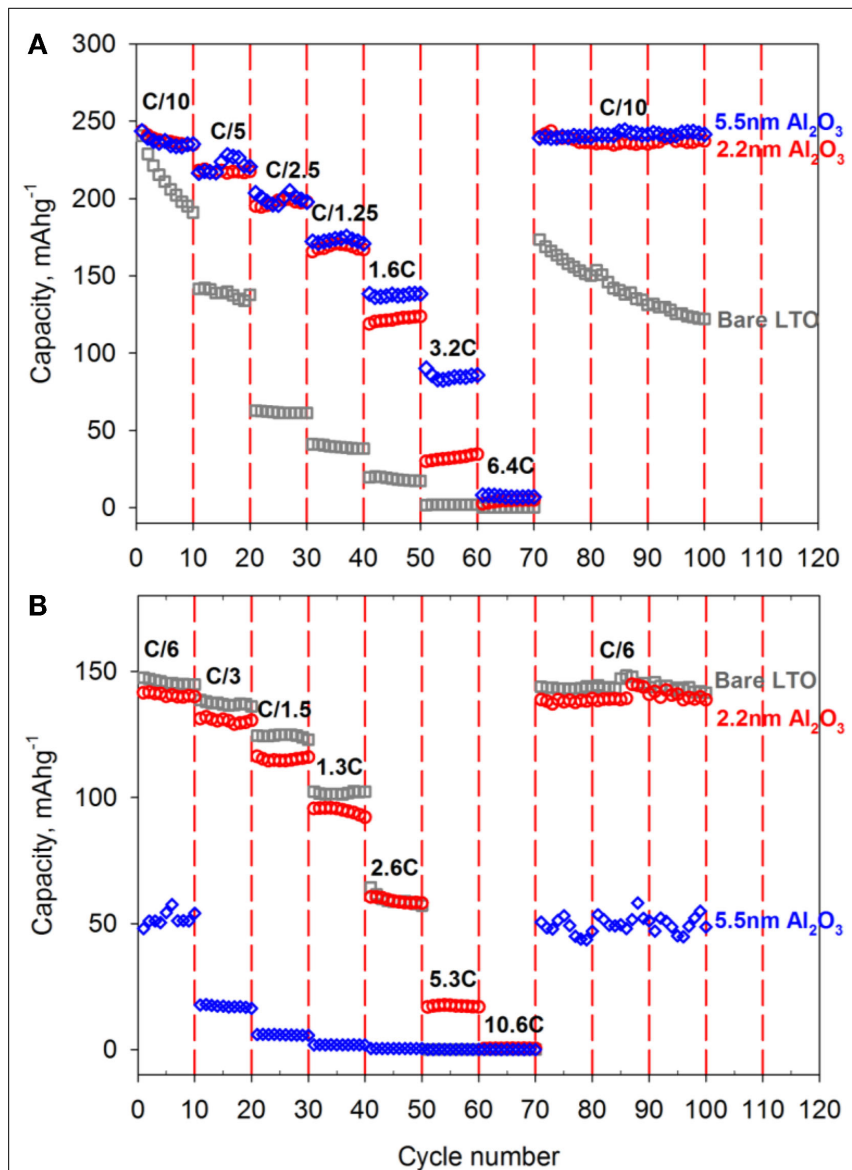

FIGURE 6 | C-rate capability of the pristine (gray), $2.2 \mathrm{~nm} \mathrm{Al} \mathrm{O}_{3}$-coated (red) and $5.5 \mathrm{~nm} \mathrm{Al} \mathrm{O}_{3}$-coated (blue) LTO electrode under the different working potential window; (A) $2.5 \mathrm{~V} \sim 1 \mathrm{mV}$ and (B) $2.5 \sim 1 \mathrm{~V}$. C-rate value was calculated by theoretical capacity and $1 \mathrm{C}$ rate in Figures $\mathbf{7 A}, \mathbf{B}$ would be defined as 250 and $150 \mathrm{mAg}^{-1}$, respectively. 
than the pristine LTO. Additionally, the inset in Figure $\mathbf{4}$ showed the voltage profile at 70th cycle of the pristine and $\mathrm{Al}_{2} \mathrm{O}_{3}$-coated LTO and the overpotential of the pristine LTO was larger than $\mathrm{Al}_{2} \mathrm{O}_{3}$-coated LTO due to large amount of SEI formed. It indicated that $\mathrm{Al}_{2} \mathrm{O}_{3}$ thin layer reduced the overpotential by suppressing electrolyte decomposition and thus increased the capacity (Scott et al., 2011).

Figure 6 shows the rate performance of $\mathrm{Al}_{2} \mathrm{O}_{3}$-coated LTO cycled in both normal and extended potential window cases were presented in Figure 6. For lower potential window in Figure 6A, capacity of either 2.2 or $5.5 \mathrm{~nm}$ thick $\mathrm{Al}_{2} \mathrm{O}_{3}$-coated LTO were outperformed the pristine LTO and capacity retention at different current density also enhanced prominently. Especially, capacity at $3.2^{\circ} \mathrm{C}$, which means LTO electrode was charged only $18 \mathrm{~min}$, had about $100 \mathrm{mAhg}^{-1}$ and it was three times more than c-rate of LTO at normal potential windows from Jung's experiment (Jung et al., 2011). In Figure 6B, capacity of $5.5 \mathrm{~nm} \mathrm{Al}_{2} \mathrm{O}_{3}$-coated LTO was much lower than the pristine and $2.2 \mathrm{~nm} \mathrm{Al}_{2} \mathrm{O}_{3}$-coated LTO because $\mathrm{Al}_{2} \mathrm{O}_{3}$ layer was not activated yet. For $2.2 \mathrm{~nm} \mathrm{Al}_{2} \mathrm{O}_{3}$ coated LTO, capacity was almost achieved same as the pristine LTO and ultrathin oxide layer did not affect the reduction of capacity significantly.
To examine the impedance change due to the effect of $\mathrm{Al}_{2} \mathrm{O}_{3}$ layers on LTO electrode, AC impedance analysis technique was carried out and shown in Figure 7. Electrochemical impedance spectroscopic results of both LTO and $\mathrm{Al}_{2} \mathrm{O}_{3}$-coated LTO were obtained at the different potential status such as OCV (Figure 7A), $1.0 \mathrm{~V}$ at discharge (Figure $7 \mathrm{~B}$ ), $0.5 \mathrm{~V}$ at discharge (Figure $7 \mathrm{C}$ ), and $2.5 \mathrm{~V}$ at charge cycle (Figure 7D). In Figure 7A, semi-circle related to the charge transfer about $R_{\mathrm{ct}}=100 \Omega$ was built up in LTO electrode whereas semi-circle of $\mathrm{Al}_{2} \mathrm{O}_{3}$-coated LTO was not fully developed. The charge transfer resistance of $\mathrm{Al}_{2} \mathrm{O}_{3}$-coated LTO electrode at open circuit potential was increased twice as much as one of LTO electrode. Presumably, the increase of charge transfer resistance in $\mathrm{Al}_{2} \mathrm{O}_{3}$-coated LTO was resulted from the insulating oxide layer on LTO surface. As lithium was intercalated into LTO until the potential reached to $1.0 \mathrm{~V}$ vs. $\mathrm{Li} / \mathrm{Li}^{+}$ (Figure $7 \mathbf{B}$ ) and $0.5 \mathrm{~V}$ vs. $\mathrm{Li} / \mathrm{Li}^{+}$(Figure 7C), charge transfer resistance was continuously increased to $500 \Omega$ for bare LTO electrode at $V_{\text {SoC }}=0.5 \mathrm{~V}$ while it had small increase from 100 to $200 \Omega$. However, impedance of $\mathrm{Al}_{2} \mathrm{O}_{3}$-coated LTO analyzed from semi-circle in Figures $\mathbf{7 B}, \mathbf{C}$ was not increased when lithium was intercalated into electrode. More surprisingly, impedance spectroscopic results at $V_{\mathrm{SoC}}=2.5 \mathrm{~V}$ vs. $\mathrm{Li} / \mathrm{Li}^{+}$, which was completed
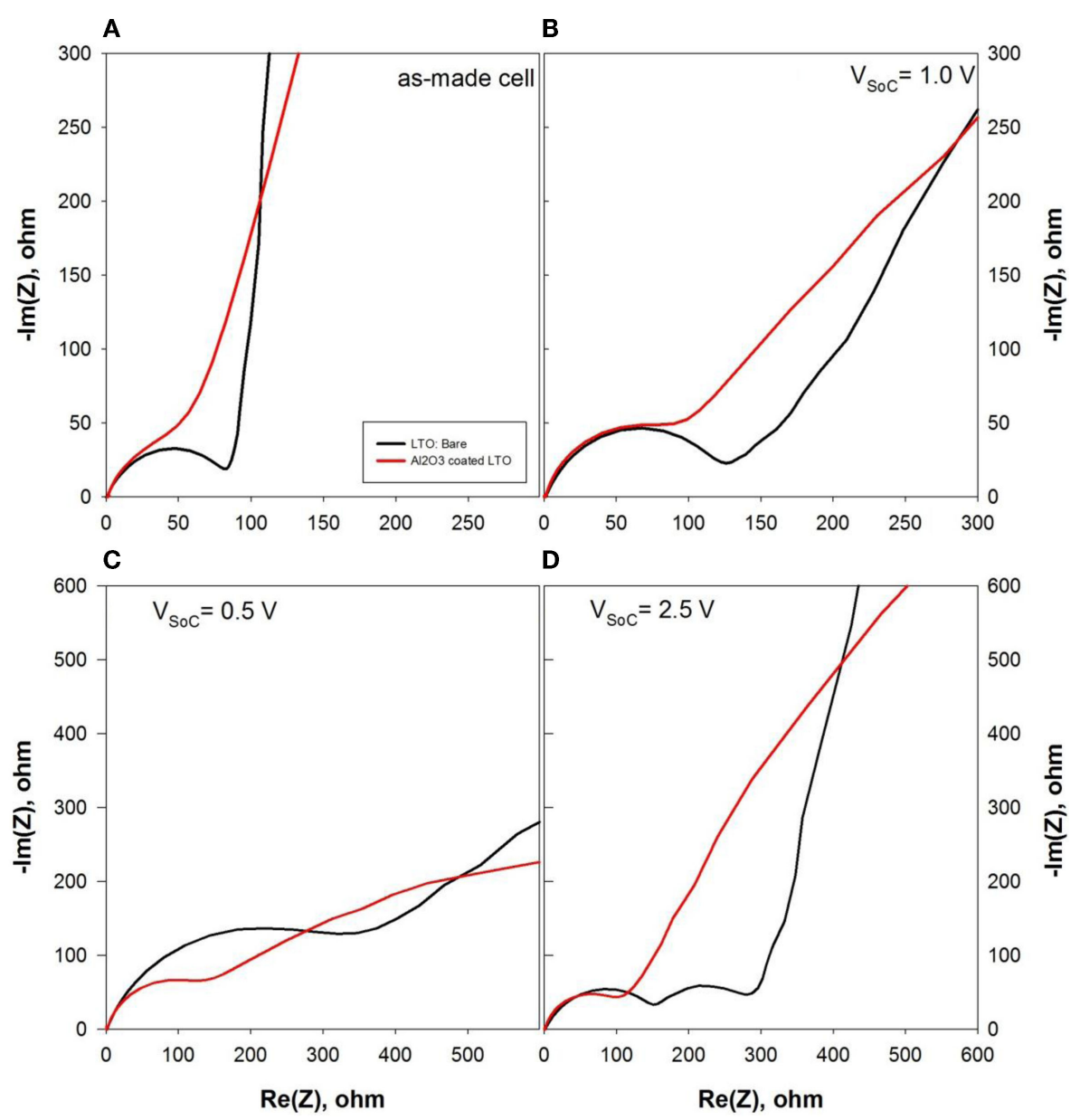

FIGURE 7 | Electrochemical impedance spectroscopy (EIS) analysis of LTO (black line) and $\mathrm{Al}_{2} \mathrm{O}_{3}$-coated LTO (red line): (A) as-made, (B) discharged to $1.0 \mathrm{~V}$, (C) discharged to $0.5 \mathrm{~V}$ and (D) charged to $2.5 \mathrm{~V} \mathrm{vs}$. $\mathrm{Li} / \mathrm{Li}^{+}$. 

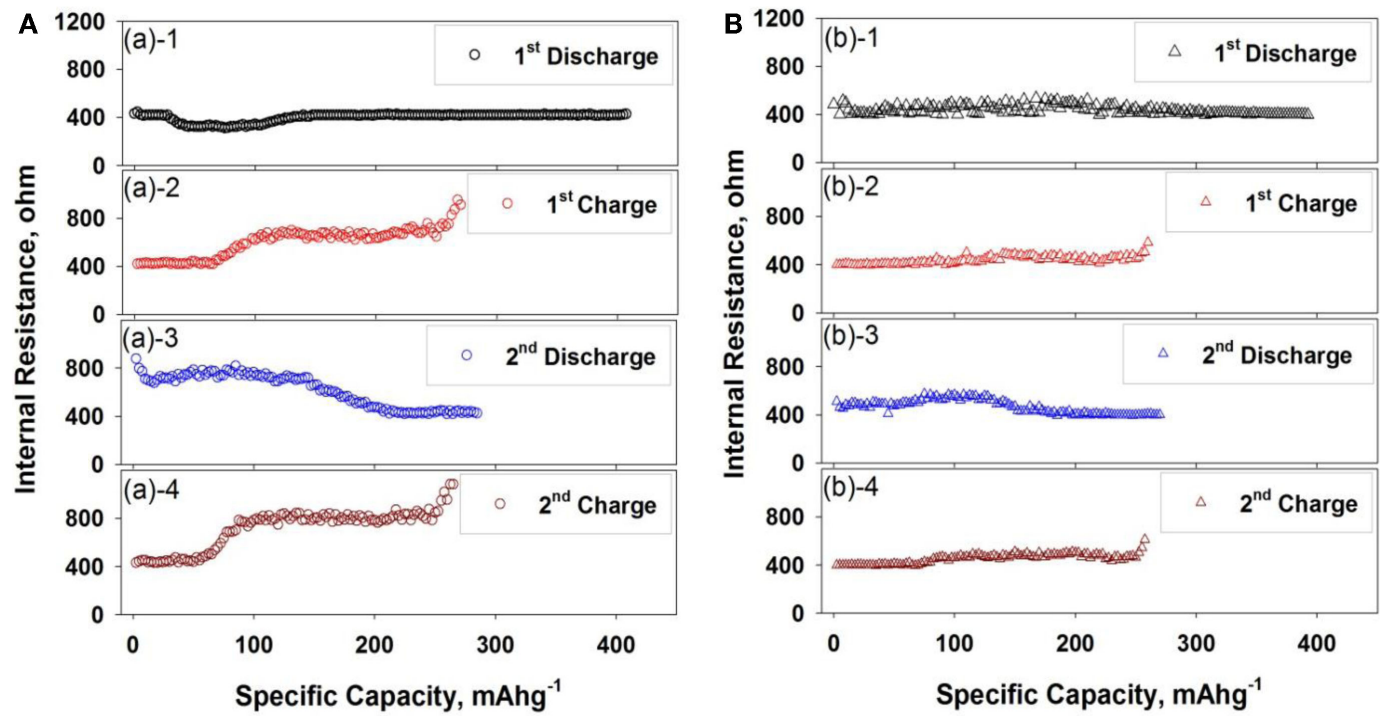

FIGURE 8 | Internal resistance change of $\mathrm{LTO}$ - and $\mathrm{Al}_{2} \mathrm{O}_{3}$-coated $\mathrm{LTO}$ at first two charge-discharge cycles: (A) $\mathrm{LTO}$ electrode and (B) $\mathrm{Al}_{2} \mathrm{O}_{3}-\mathrm{Coated}$ LTO electrode.

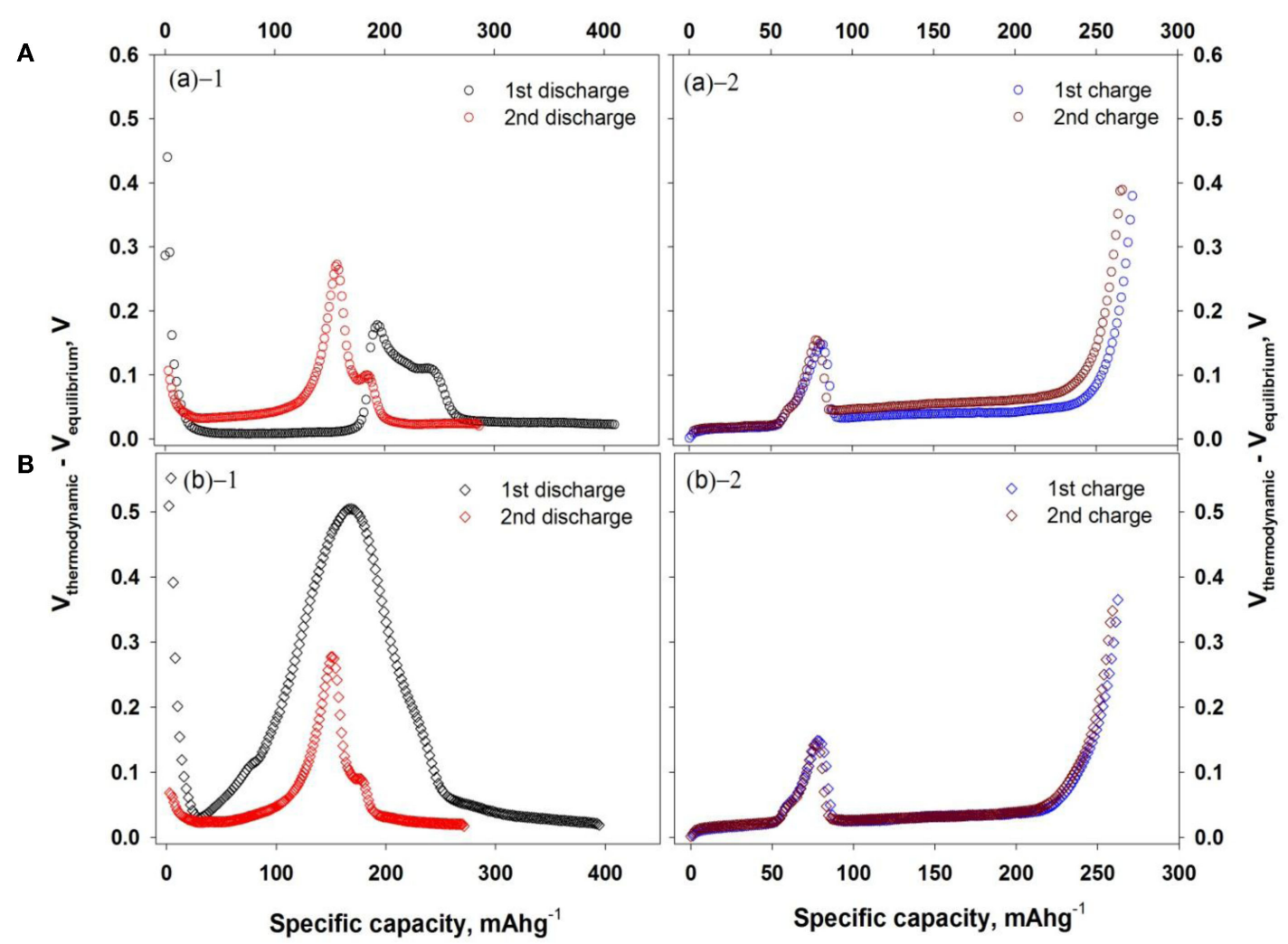

FIGURE 9 | Thermodynamic and equilibrium potential differences of LTO- and $\mathrm{Al}_{2} \mathrm{O}_{3}$-coated LTO at first two charge-discharge cycles from galvanostatic intermittent titration technique (GITT): (A) LTO electrode and (B) $\mathrm{Al}_{2} \mathrm{O}_{3}$-coated LTO electrode

as first charge-discharge cycle showed definite changes between LTO- and $\mathrm{Al}_{2} \mathrm{O}_{3}$-coated LTO electrodes. For bare LTO, there were two semi-circles, which were related to the charge transfer resistance and the SEI layer growth, respectively. On the other hand, electrochemical impedance spectroscopy of $\mathrm{Al}_{2} \mathrm{O}_{3}$-coated LTO only had one semi-circle even though the cell was finished the entire charge-discharge cycle. It presented that $\mathrm{Al}_{2} \mathrm{O}_{3}$ layers on LTO surface were initially increased the intrinsic cell resistance 
due to the insulting property of oxides. However, as lithium continuously reacted with LTO-electrolyte interface during charging and discharging cycles, $\mathrm{Al}_{2} \mathrm{O}_{3}$ layers suppressed SEI formation and played as the protective layers like an artificial SEI layers. Additionally, capacity degradation was extenuated by the $\mathrm{Al}_{2} \mathrm{O}_{3}$ layers on the surface of LTO.

For investigating the nature of $\mathrm{Al}_{2} \mathrm{O}_{3}$ layers on LTO surface, the internal resistance and potential difference between thermodynamic and equilibrium state were measured by galvanostatic intermittent titration technique (GITT) and displayed in Figures 8 and 9, respectively. In Figure 8, the internal resistance of bare LTO (Figure 8A) was changed with respect to lithium concentration in LTO upon charging-discharging cycle while one of $\mathrm{Al}_{2} \mathrm{O}_{3}$-coated LTO was maintained as the similar values. At first discharge cycle in both LTO- and $\mathrm{Al}_{2} \mathrm{O}_{3}$-coated LTO, the internal resistance of $\mathrm{Al}_{2} \mathrm{O}_{3}$-coated LTO was slightly higher than that of bare LTO. It was also correlated with the previous results in Figure 7 and linked to the insulating behavior of oxide films.

To delve into the dissimilar behavior of first discharge voltage profile in Figures $\mathbf{4 A}, \mathbf{C}$, potential differences $\left(V_{\mathrm{D}}\right)$ between thermodynamic $\left(V_{\text {thermo }}\right)$ and quasi-equilibrium potential ( $V_{\text {equilibrium }}$ ) were calculated from the GITT results and presented in Figure 9. In order to obtain the quasi-equilibrium potential, the constant current was applied to the cell within the certain time period (360s) and rested without current or voltage during the other time period (1800 s). In Figure 9A, the peak value of $V_{\mathrm{D}}$ was occurred at the capacity of $200 \mathrm{mAhg}^{-1}$, which was located at lower cut-off voltage regime than $1 \mathrm{~V} \mathrm{vs.} \mathrm{Li} / \mathrm{Li}^{+}$and the

\section{References}

Ahn, D., and Xiao, X. (2011). Vertically aligned graphene electrode for lithium ion battery with high rate capability. Electrochem. Commun. 13, 209-212. doi:10. 1016/j.elecom.2010.12.016

Aldon, L., Kubiak, P., Womes, M., Jumas, J. C., Olivier-Fourcade, J., Tirado, J. $\mathrm{L}$., et al. (2004). Chemical and electrochemical Li-insertion into the $\mathrm{Li}_{4} \mathrm{Ti}_{5} \mathrm{O}_{12}$ spinel. Chem. Mater. 16, 5721-5725. doi:10.1021/cm0488837

Amine, K., Belharouak, I., Chen, Z. H., Tran, T., Yumoto, H., Ota, N., et al. (2010). Nanostructured anode material for high-power battery system in electric vehicles. Adv. Mater. 22, 3052-3057. doi:10.1002/adma.201090091

Bryngelsson, H., Stjerndahl, M., Gustafsson, T., and Edstr, K. (2007). How dynamic is the SEI? J. Power Sources 174, 970-975. doi:10.1016/j.jpowsour.2007.06.050

Chen, Z. H., Qin, Y., Amine, K., and Sun, Y. K. (2010). Role of surface coating on cathode materials for lithium-ion batteries. J. Mater. Chem. 20, 7606-7612. doi:10.1039/c0jm00154f

Cho, J., Kim, Y. J., Kim, T. J., and Park, B. (2001). Zero-strain intercalation cathode for rechargeable Li-ion cell. Angew. Chem. Int. Ed. Engl. 40, 3367-3369. doi:10. 1002/1521-3773(20010917)40:18<3367::AID-ANIE3367>3.0.CO;2-A

Colbow, K. M., Dahn, J. R., and Haering, R. R. (1989). Structure and electrochemistry of spinel oxides $\mathrm{LiTi}_{2} \mathrm{O}_{4}$ and $\mathrm{Li}_{4 / 3} \mathrm{Ti}_{5 / 3} \mathrm{O}_{4}$. J. Power Sources $26,397-402$. doi:10.1016/0378-7753(89)80152-1

Jung, H. G., Myung, S. T., Yoon, C. S., Son, S. B., Oh, K. H., Amine, K., et al. (2011). Microscale spherical carbon-coated $\mathrm{Li}_{4} \mathrm{Ti}_{5} \mathrm{O}_{12}$ as ultra high power anode material for lithium batteries. Energy Environ. Sci. 4, 1345-1351. doi:10.1039/ c0ee00620c

Jung, Y. S., Cavanagh, A. S., Dillon, A. C., Groner, M. D., Georgee, S. M., and Lee, S. H. (2010a). Enhanced stability of $\mathrm{LiCoO}_{2}$ cathodes in lithium-ion batteries using surface modification by atomic layer deposition. J. Electrochem. Soc. 157, A75-A81. doi:10.1149/1.3258274

Jung, Y. S., Cavanagh, A. S., Riley, L. A., Kang, S. H., Dillon, A. C., Groner, M. D., et al. (2010b). Ultrathin direct atomic layer deposition on composite electrodes peaks were shifted to the higher cut-off voltage regime at second discharge cycle. In contrast to bare LTO, $V_{D}$ of $\mathrm{Al}_{2} \mathrm{O}_{3}$-coated LTO at first discharge cycle had higher peaks, which means less favorable energy state than bare LTO. However, $V_{\mathrm{D}}$ at second cycle was similar to one of bare LTO since $\mathrm{Al}_{2} \mathrm{O}_{3}$ layer was activated with reacting to lithium at lower cut-off potential regimes. In charging cycle, the peak position of $V_{\mathrm{D}}$ between bare and $\mathrm{Al}_{2} \mathrm{O}_{3}$ coated LTO were identical to each other. In Figure 9A (2), $V_{\mathrm{D}}$ in bare LTO from first to second charging cycle was increased because it was continuously increased its resistance due to the SEI layer growth. These results were complementary to the evidence of SEI layer growth showing in Figure 7, too.

\section{Conclusion}

Atomic layer deposited $\mathrm{Al}_{2} \mathrm{O}_{3}$ coating was introduced as the passivation layer on LTO electrodes to stabilize the cycling performance at lower voltage down to $1 \mathrm{mV}$ vs. $\mathrm{Li} / \mathrm{Li}^{+}$. It has also been demonstrated that ultrathin $\mathrm{Al}_{2} \mathrm{O}_{3}$ film significantly improved the C-rate capability of LTO electrode at lower potential window. Compared to the normal potential window from 2.5 to $1 \mathrm{~V}$, lower potential window enable to activate the $\mathrm{Al}_{2} \mathrm{O}_{3}$ layer to transport $\mathrm{Li}$ ion and provide the higher specific capacity at electrode level and energy density at cell level.

\section{Acknowledgments}

The authors would like to thank Dr. Curtis Wong for SEM characterization.

for highly durable and safe Li-ion batteries. Adv. Mater. 22, 2172-2176. doi:10. 1002/adma.200903951

Liao, J. Y., Xiao, X., Higgins, D. C., Lee, D. U., Hassan, F., and Chen, Z. W. (2013). Hierarchical $\mathrm{Li}_{4} \mathrm{Ti}_{5} \mathrm{O}_{12}-\mathrm{TiO}_{2}$ composite microsphere consisting of nanocrystals for high power Li-ion batteries. Electrochim. Acta 108, 104-111. doi:10.1016/j. electacta.2013.06.073

Liao, J. Y., Chabot, V., Meng Gu, M., Wang, C., Xiao, X., and Chen, Z. W. (2014). Dual phase $\mathrm{Li}_{4} \mathrm{Ti}_{5} \mathrm{O}_{12}-\mathrm{TiO}_{2}$ nanowire arrays as integrated anodes for high rate lithium-ion batteries. Nano Energy 9, 383-391. doi:10.1016/j.nanoen.2014. 06.032

Lu, W., Belharouak, I., Liu, L., and Amine, K. (2007). Electrochemical and thermal investigation of $\mathrm{Li}_{4 / 3} \mathrm{Ti}_{5 / 3} \mathrm{O}_{4}$ spinel. J. Electrochem. Soc. 154, A114-A118. doi:10. $1149 / 1.2402117$

Oh, Y., Ahn, D., Nam, S., and Park, B. (2010). The effect of $\mathrm{Al}_{2} \mathrm{O}_{3}$-coating coverage on the electrochemical properties in $\mathrm{LiCoO}_{2}$ thin films. J. Solid State Electrochem. 14, 1235-1240. doi:10.1007/s10008-009-0946-7

Ohzuku, T., Ueda, A., and Yamamoto, N. (1995). Zero-strain insertion material of $\mathrm{Li}_{4 / 3} \mathrm{Ti}_{5 / 3} \mathrm{O}_{4}$ for rechargeable lithium cells. J. Electrochem. Soc. 142, 1431-1435. doi:10.1149/1.2048592

Riley, L. A., Cavanagh, A. S., George, S. M., Jung, Y. S., Yan, Y., Lee, S. H., et al. (2010). Conformal surface coatings to enable high volume expansion Li-ion anode materials. Chemphyschem 11, 2124-2130. doi:10.1002/cphc.201000158

Ronci, F., Reale, P., Scrosati, B., Panero, S., Albertini, V. R., Perfetti, P., et al. (2002). High-resolution in-situ structural measurements of the $\mathrm{Li}_{4 / 3} \mathrm{Ti}_{5 / 3} \mathrm{O}_{4}$ “zero-strain" insertion material. J. Phys. Chem. B 106, 3082-3086. doi:10.1021/ jp013240p

Scott, I. D., Jung, Y. S., Cavanagh, A. S., Yan, Y., Dillon, A. C., George, S. M., et al. (2011). Ultrathin coatings on nano-LiCoO2 for Li-ion vehicular applications. Nano Lett. 11, 414-418. doi:10.1021/nl1030198

Takami, N., Hoshina, K., and Inagaki, H. (2011). Lithium diffusion in $\mathrm{Li}_{4 / 3} \mathrm{Ti}_{5 / 3} \mathrm{O}_{4}$ particles during insertion and extraction. J. Electrochem. Soc. 158, A725-A730. doi:10.1149/1.3574037 
Tarascon, J. M., and Armand, M. (2001). Issues and challenges facing rechargeable lithium batteries. Nature 414, 359-367. doi:10.1038/35104644

Wang, F., Hong, J., Van Der Ven, A., and Graetz, J. (2012). Phase transitions of spinel $\mathrm{Li}_{4} \mathrm{Ti}_{5} \mathrm{O}_{12}$ with multiple-Li intercalation, $221^{\text {st }}$ ECS meeting. Electrochem. Soc. Available at: http://ma.ecsdl.org/content/MA2012-01/9/525.full.pdf

Xiao, X., Lu, P., and Ahn, D. (2011). Ultrathin multifunctional oxide coatings for lithium ion batteries. Adv. Mater. 23, 3911-3915. doi:10.1002/adma. 201101915

Zaghib, K., Armand, M., and Gauthier, M. (1998). Electrochemistry of anodes in solid-state Li-ion polymer batteries. J. Electrochem. Soc. 145, 3135-3140. doi:10.1039/c3nr05181a
Conflict of Interest Statement: The authors declare that the research was conducted in the absence of any commercial or financial relationships that could be construed as a potential conflict of interest.

Copyright (C) 2015 Ahn and Xiao. This is an open-access article distributed under the terms of the Creative Commons Attribution License (CC BY). The use, distribution or reproduction in other forums is permitted, provided the original author(s) or licensor are credited and that the original publication in this journal is cited, in accordance with accepted academic practice. No use, distribution or reproduction is permitted which does not comply with these terms. 